\title{
Characterization of internalin genes in Listeria monocytogenes from food and humans, and their association with the invasion of Caco-2 cells
}

\author{
Xudong Su' ${ }^{1}$ Guojie Cao ${ }^{2}$, Jianmin Zhang ${ }^{1}$, Haijian Pan ${ }^{1}$, Daofeng Zhang ${ }^{1}$, Dai Kuang ${ }^{1}$, Xiaowei Yang ${ }^{1}$,
} Xuebin $\mathrm{Xu}^{3}$, Xianming Shi ${ }^{{ }^{*}}$ and Jianghong Meng ${ }^{2^{*}}$

\begin{abstract}
Background: Internalins are surface proteins that are utilized by Listeria monocytogenes to facilitate its invasion into human intestinal epithelial cells. The expression of a full-length InIA is one of essential virulence factors for L. monocytogenes to cross the intestinal barrier in order to invade epithelial cells.

Results: In this study, the gene sequences of inIA in 120 L. monocytogenes isolates from food $(n=107)$ and humans $(n=13)$ were analyzed. Premature stop codon (PMSC) mutations in inlA were identified in 51 isolates (50 from food and 1 from human). Six mutation types of PMSCs were identified. Among the 51 isolates with PMSCs in in/A, there were 44 serogroup 1/2c, 3c isolates from food, of which seven belonged to serogroups 1/2a, 3a. A total of 153,382 SNPs in 2247 core genes from 42 genomes were identified and used to construct a phylogenetic tree. Serotype 1/2C isolates with inIA PMSC mutations were grouped together. Cell culture studies on 21 isolates showed that the invasion to Caco-2 cells was significantly reduced among isolates with inIA PMSC mutations compared to those without PMSC mutations $(P<0.01)$. The PMSC mutations in inlA correlated with the inability of the $L$. monocytogenes isolates to invade Caco-2 cells (Pearson's coefficient 0.927, $P<0.01$ ).
\end{abstract}

Conclusion: Overall, the study has revealed the reduced ability of $L$. monocytogenes to invade human intestinal epithelial cells in vitro was linked to the presence of PMSC mutations in in/A. Isolates with PMSC mutations shared the same genomic characteristics indicating the genetic basis on the potential virulence of L. monocytogenes invasion.

Keywords: L. monocytogenes, Internalins, in/A, PMSC mutation, Invasion

\section{Introduction}

Listeria monocytogenes is a foodborne pathogen that can cause gastroenteritis in healthy individuals, meningitis in immunocompromised individuals, and abortions in pregnant women. It has a high case fatality rate of $20-30 \%$ [9].

\footnotetext{
*Correspondence: xmshi@sjtu.edu.cn; jmeng@umd.edu

${ }^{1}$ Department of Food Science and Technology, MOST-USDA Joint

Research Center for Food Safety, School of Agriculture and Biology, State Key Lab of Microbial Metabolism, Shanghai Jiao Tong University, Shanghai 200240, China

2 Department of Nutrition \& Food Science, University of Maryland, College Park, MD 20742, USA

Full list of author information is available at the end of the article
}

Many types of foods, including meat, poultry, dairy, and vegetable products have been implicated as transmission vehicles for $L$. monocytogenes $[1,44,63]$. In view of the foodborne route of transmission of L. monocytogenes and the potential severity of listeriosis, strict food safety regulations have been established, including "zero tolerance" approach for ready-to-eat food in the United States [4].

Listeria monocytogenes possesses an array of virulence factors, which allow it to infect, survive, and replicate in a variety of host cell types. Numerous studies have been conducted to investigate the adhesion, invasion, and/or virulence regulation of $L$. monocytogenes. The roles of virulence factors (i.e., PrfA, ActA, InlA, InlB, InlC, LAP, 
Ami, p60, Auto) in L. monocytogenes pathogenesis have been well characterized in different cell types or animal models $[2,5,9,12,13,25,33,42,53,56]$. Surface proteins of $L$. monocytogenes associate with a variety of different cell surface structures. Internalin surface molecules harbor amino acid leucine-rich repeats that interact with specific host-receptors to promote the invasion of $L$. monocytogenes into selected host cells [3]. InlA identified as a virulence factor in 1991 [18] is a covalently linked bacterial cell-wall protein that binds to E-cadherin on the host epithelial cell, and is associated with crossing the intestinal barrier $[9,38,40]$. Entry into host cells by bacteria has been investigated in great detail. The interaction of internalin with its receptor, E-cad, has been the focus of several studies $[35,46,47]$. InlA has been used as a virulence marker for detecting L. monocytogenes in food [8, $23,28,41,50]$.

Listeria monocytogenes carrying premature stop codon (PMSC) mutations in inlA produce a truncated form of InlA that is secreted rather than anchored to the bacterial cell wall [16, 20,37]. A total of 21 mutation types of inlA have been identified $[19,20,58]$. The strains with truncated InlA were virulence-attenuated in a guinea pig model [36, 59], and exhibited attenuated invasion of Caco-2 human intestinal epithelial cells $[11,15]$. L. monocytogenes is a diverse species with a structured population that includes at least three phylogenetic lineages, and two lineages (I and II) are common [43]. Serotypes $1 / 2 \mathrm{~b}$ and $4 \mathrm{~b}$ belong to lineage $\mathrm{I}$, whereas serotypes $1 / 2 \mathrm{a}$ and $1 / 2 \mathrm{c}$ belong to lineage II. Lineage II strains carry inlA PMSC mutations more frequently than lineage I strains $[39,48]$. However, PMSC in inlA have also be identified in isolates from human patients, indicating their ability in causing listeriosis [22,37]. Additional genomics data would provide useful information to determine potential virulence of $L$. monocytogenes with PMSC mutations.

Several studies on L. monocytogenes conducted in China focused on the distribution, molecular subtyping and antimicrobial susceptibility of the pathogen recovered from ready-to-eat (RTE) food products [7, 60, 61]. PMSCs in inlA and characteristics of L. monocytogenes genomes have not been reported. The aim of the present study was to characterize internalin gene and their association with the ability to invade host cells, and to conduct phylogenetic analysis of selected genomes of $L$. monocytogenes recovered from both food and humans in Shanghai, China.

\section{Materials and methods \\ Bacterial strains}

A total of $120 \mathrm{~L}$. monocytogenes isolates recovered from 2004 to 2013 in Shanghai, China, were examined in the study, including 30 isolates from duck, 28 from chicken,
27 from beef, 18 from pork, 2 from vegetables, 1 from fish, and 1 from yogurt as well as 13 clinical isolates that were collected from patients admitted to three hospitals in Shanghai. The clinical isolates were recovered from 11 blood and two cerebrospinal fluid (CSF) specimens. All isolates had previously been characterized by serogroup and lineage typing [52]. Listeria innocua ATCC33090, L. monocytogenes EGD-e and L. monocytogenes serotype 4b strain $4 \mathrm{bG}$ were used as reference strains for Caco-2 cell invasion assay.

\section{DNA sequencing}

The sequencing of inlA gene was performed to determine inlA mutation types. Mutation types 1-18 have been summarized previously by Van Stelten et al. [58]. Previously published DNA primer sets were used for PCR amplification and sequencing of inlA [39]. PCR products were sequenced at Shenggong Inc, Shanghai, China. The inlA sequences of the $120 \mathrm{~L}$. monocytogenes isolates were assembled using Seqman software (DNASTAR, Lasergene), and aligned using the CLUSTAL W program (MEGALIGN, DNASTAR, Lasergene). A phylogenetic tree was constructed using the maximum likelihood method [55]. DNAMAN v.6.0 software (Lynnon Biosoft, Qc, Canada) was used for the translation of DNA into protein.

\section{Whole genome sequencing analysis}

Whole genome sequencing was performed on four $L$. monocytogenes isolates, including three food isolates carrying PMSC mutations in inlA and one human isolate with full-length inlA, using Illumina MiSeq (Illumina, San Diego, CA) with MiSeq Reagent Kit v2 (500 cycle), Nextera XT DNA Sample Preparation kit, and Nextera XT Index Kit. Genomics data were annotated using the NCBI Prokaryotic Genomes Annotation Pipeline. All $L$. monocytogenes genomes were annotated at NCBI [51].

\section{Phylogenetic relationship of $L$. monocytogenes genomes}

Phylogenetic analysis of 42 genomes was performed (Table 1), including four genomes from the current study, 17 genomes from our pervious study [62] and 21 publicly available genomes. The deduced amino acid sequences of all CDSs from the 42 genomes were adjusted to a prescribed format and were grouped into homologous clusters using OrthoMCL version 2.0.9 [29] based on sequence similarity. The BLAST reciprocal best hit algorithm [34] was employed with a $70 \%$ match cutoff and 1e-5 e-value cutoff, and Markov Cluster Algorithms (MCL) [14] were applied with an inflation index of 1.5. For each orthologous cluster, protein sequences were aligned using Clustal Omega version 1.2.1 [49]. Single nucleotide polymorphisms (SNPs) were identified from 
Table 1 Origin and genetic characteristics of 42 L. monocytogenes isolates

\begin{tabular}{|c|c|c|c|c|c|c|c|}
\hline Strain & Serotype/lineage & $\begin{array}{l}\text { Genome size } \\
\text { (Mb) }\end{array}$ & GC content (\%) & Source & Year & Country & GenBank accession \\
\hline SHL001 & 1/2a, II & 2.95 & 37.9 & $\mathrm{CSF}^{\mathrm{C}}$ & 2007 & China & APIB00000000 \\
\hline SHL002 & $1 / 2 b, l$ & 3.12 & 37.9 & Blood & 2007 & China & APIC00000000 b \\
\hline SHL003 & $1 / 2 b, l$ & 3.00 & 37.9 & Blood & 2008 & China & LVYC00000000 \\
\hline SHLO04 & $1 / 2 a, \|$ & 3.01 & 37.8 & Blood & 2008 & China & APID00000000 b \\
\hline SHLO05 & $1 / 2 \mathrm{a}, \|$ & 2.88 & 37.9 & Blood & 2008 & China & APIE00000000 \\
\hline SHL006 ${ }^{\mathrm{a}}$ & $1 / 2 c, \|$ & 2.93 & 37.9 & Blood & 2010 & China & APIF00000000 \\
\hline SHL007 & $1 / 2 b, 1$ & 2.98 & 37.9 & Blood & 2011 & China & APIG00000000 b \\
\hline SHL008 & $1 / 2 b, I$ & 3.01 & 37.9 & Blood & 2012 & China & APIH00000000 \\
\hline SHLOO9 & $1 / 2 \mathrm{a}, \|$ & 2.87 & 37.9 & Blood $^{d}$ & 2012 & China & APII00000000 \\
\hline SHL010 & $1 / 2 \mathrm{~b} / \mathrm{l}$ & 3.08 & 37.9 & Blood & 2012 & China & APIJ00000000 \\
\hline SHL011 & $1 / 2 a, \|$ & 2.87 & 37.9 & Blood & 2011 & China & APIK00000000 \\
\hline SHL012 & $1 / 2 b, I$ & 2.93 & 37.9 & $\mathrm{CSF}^{\mathrm{C}}$ & 2010 & China & APIL00000000 \\
\hline SHL013 & $1 / 2 \mathrm{a}, \|$ & 2.86 & 37.9 & Blood $^{d}$ & 2012 & China & APIM00000000 \\
\hline LM430 & $1 / 2 c, \|$ & 2.95 & 37.9 & Pork & 2008 & China & AWWQ00000000 \\
\hline LM438 & $1 / 2 a, \|$ & 2.96 & 38.7 & Beef & 2008 & China & AWWR00000000 b \\
\hline LM440 & $1 / 2 c, \|$ & 2.97 & 37.7 & Fish & 2008 & China & AWWS00000000 \\
\hline LM469 & $1 / 2 \mathrm{a}, \|$ & 2.95 & 38.7 & Bean & 2004 & China & AWWT00000000 \\
\hline LM470 & $1 / 2 c, \|$ & 2.94 & 37.8 & Vegetable & 2004 & China & AWW $000000000^{b}$ \\
\hline SHL12-2 ${ }^{\mathrm{a}}$ & $1 / 2 c, \|$ & 2.99 & 37.9 & Pork & 2012 & China & LRTW000000000 \\
\hline SHL12-22 & $1 / 2 \mathrm{a}, \|$ & 2.97 & 37.9 & Duck & 2012 & China & LRTX00000000 \\
\hline SHL13-12 & $1 / 2 \mathrm{a}, \|$ & 2.98 & 37.9 & Duck & 2013 & China & LRTY00000000 \\
\hline EGD-e & 1/2a, II & 2.94 & 38.0 & Rabbit & 1926 & UK & AL591824.1 \\
\hline 104035 & $1 / 2 \mathrm{a}, \|$ & 2.90 & 38.0 & Human & 1968 & U.S. & CP002002 \\
\hline F6900 & $1 / 2 \mathrm{a}, \|$ & 2.97 & 37.7 & Human & 1989 & U.S. & AARU02000000 \\
\hline$J 2818$ & $1 / 2 a, \|$ & 2.97 & 37.7 & Human & 2000 & U.S. & AARX02000000 \\
\hline J0161 & $1 / 2 \mathrm{a}, \|$ & 3.00 & 37.9 & Human & 2000 & U.S. & CP002001 \\
\hline $08-5578$ & $1 / 2 \mathrm{a}, \|$ & 3.03 & 38.0 & Human & 2008 & Canada & СР001602.1 \\
\hline 08-5923 & $1 / 2 \mathrm{a}, \|$ & 3.00 & 38.0 & Human & 2008 & Canada & СР001604 \\
\hline SLCC5850 & $1 / 2 \mathrm{a}, \|$ & 2.91 & 38.0 & Rabbit & 1924 & UK & FR733647 \\
\hline F6854 & $1 / 2 \mathrm{a}, \|$ & 2.95 & 37.8 & Hot dog & 1988 & U.S. & AADQ01000000 \\
\hline C1-387 & $1 / 2 \mathrm{a}, \|$ & 2.99 & 37.9 & Food & 1999 & U.S. & CP006591 \\
\hline FSL N3-165 & $1 / 2 \mathrm{a}, \|$ & 2.88 & 37.8 & Soil & N.A. & U.S. & AARQ02000000 \\
\hline SLCC2755 & $1 / 2 b, \mid$ & 2.97 & 38.1 & Human & N.A. & N.A. & NC_018587 \\
\hline FSL J1-194 & $1 / 2 b, l$ & 2.99 & 37.8 & Human & N.A. & U.S. & AARJ00000000 \\
\hline R2-502 & $1 / 2 b, l$ & 3.03 & 37.9 & Food & 1994 & U.S. & CP006594 \\
\hline FSL R2-503 & $1 / 2 b, I$ & 2.99 & 37.8 & Human & 1994 & U.S. & AARR00000000 \\
\hline N1-011A & $1 / 2 b, I$ & 3.01 & 37.9 & Environment & N.A. & U.S. & СР006597 \\
\hline J1-108 & $4 b, 1$ & 2.98 & 38.0 & N.A. & 2013 & U.S. & NC_021825.1 \\
\hline F2365 & $4 b, 1$ & 2.90 & 37.9 & Human & 1985 & U.S. & AE017262.2 \\
\hline FSL R2-561 & $1 / 2 c, \|$ & 2.97 & 38.0 & N.A. & N.A. & N.A. & NC_017546 \\
\hline SLCC 2372 & $1 / 2 c, \|$ & 2.97 & 38.0 & N.A. & N.A. & N.A. & NC_018588 \\
\hline J2-031 & $1 / 2 c, \|$ & 2.96 & 37.9 & Human & 1996 & U.S. & CP006593 \\
\hline
\end{tabular}

a Isolate with a premature stop codon (PMSC) mutation in inIA

b Isolate whose whole genome was sequenced in a previous study [62]

c Cerebrospinal fluid

d Caused human death 
core genes in the genome. To reconstruct evolutionary relatedness, a phylogenetic tree was constructed using the maximum likelihood method [55].

\section{Invasion assays}

Invasion assays on $21 \mathrm{~L}$. monocytogenes isolates were performed using Caco-2 (ATCC HTB-37) cells as previously described $[10,54]$. Briefly, the cells were harvested from confluent cell cultures and suspended at a concentration of $1 \times 10^{5}$ cells $/ \mathrm{mL}$ in Dulbecco's modified Eagle's medium (DMEM) containing 10\% fetal bovine serum and $1 \%$ non-essential amino acids. A 24-well tissue culture plate was seeded with $1 \mathrm{~mL}$ per well to confluence for $48 \mathrm{~h}$ at a final density of approximately $3.5 \times 10^{5}$ cells per well. The invasion assays were performed by incubating L. monocytogenes with Caco-2 epithelial cells at a ratio of 100:1 [10,54]. The viable count was determined retrospectively by culturing tenfold serial dilution in PBS onto freshly prepared brain heart infusion (BHI) agar plates. L. monocytogenes and epithelial cells were coincubated for $1 \mathrm{~h}$ at $37{ }^{\circ} \mathrm{C}$ under $5 \% \mathrm{CO}_{2}$ air atmosphere. To determine the number of the bacterium that had been internalized into epithelial cells, $90 \mathrm{~min}$ incubation in DMEM medium containing $150 \mu \mathrm{g} / \mathrm{mL}$ gentamicin (Sigma, St. Louis, Missouri, USA) was performed in each well to kill extracellular bacterial cells. After washing three times with PBS, epithelial cells were then lysed to release the intracellular bacterial cells. The number of L. monocytogenes that had invaded the cells was determined by plating serial dilutions of the suspensions onto BHI agar plates. The detection limit of the cell invasion assay was $33 \mathrm{CFU} / \mathrm{mL}$. Blank wells were used as negative controls, and each assay was performed in triplicate and replicated three times. L. innocua ATCC33090, and $L$. monocytogenes strains EGD-e and $4 \mathrm{bG}$ were included in the invasion assay as reference strains. Data from three replicates were included in statistical analysis using SAS software 9.1 (SAS Institute Inc., Cary, NC, USA) to determine differences between bacterial count means among the different isolates. $P$-values of $<0.05$ were considered as statistically significant.

\section{Results}

Mutation genotype in inlA of $L$. monocytogenes

The $i n l A$ gene was successfully amplified in the $120 \mathrm{~L}$. monocytogenes isolates from food and humans. Mutation types 4, 6, 8, 11, 12 and 19 were identified among 51 of the 120 isolates (Table 2, Additional file 1: Table S1). Forty-three food isolates and one human isolate belonged to serogroup $1 / 2 c$, 3c. Seven food isolates belonged to serogroups $1 / 2 \mathrm{a}$ and $3 \mathrm{a}$. Serogroup $1 / 2 \mathrm{~b}$ and $3 \mathrm{~b}$ isolates possessed no PMSC mutations in their inlA genes. PMSC mutation type 19 was identified in 10 foods isolates, which expressed a truncated InlA protein (325aa length). Human isolate SHL013 (serotype 1/2a) had 9 nucleotide deletions in inlA. Human isolate SHL006 carried mutation type 12 in inlA.

\section{Phylogenetic analysis of inlA}

Phylogenetic analysis revealed a clear separation of inlA sequences between $L$. monocytogenes lineages I and II (Fig. 1). One branch contained all of the 29 isolates of serotypes $1 / 2 \mathrm{~b}$ and $3 \mathrm{~b}$ (Lineage I). Another branch contained $1 / 2 \mathrm{a}$ and $3 \mathrm{a}$ (except isolate SHL12-13), and 1/2c and $3 c$ isolates (Lineage II). The clustering of the $\operatorname{inl} A$ sequences containing PMSC mutations was evident and consistent with the lineage classification of the isolates (Fig. 1). Most isolates of serogroup 1/2c, 3c with nonsense mutations were grouped together. Ten isolates with mutation type 19 in inlA were grouped together in the region highlighted in green in Fig. 1.

\section{Phylogenetic analysis of $L$. monocytogenes genomes}

The genome of four L. monocytogenes isolates from the current was assembled, including serotype $1 / 2 \mathrm{c}$ strain SHL12-2 (16 contigs, $3.01 \mathrm{Mb}, 583,457$ bp N50 contig size, and 2978 identified genes), serotype 1/2a strain SHL12-22 (20 contigs, $3.02 \mathrm{Mb}, 506,776$ bp N50 contig size, and 2943 identified genes), serotype $1 / 2$ a strain SHL13-12 (17 contigs, $2.99 \mathrm{Mb}, 524,215$ bp N50 contig size, and 2884 identified genes), and serotype $1 / 2 \mathrm{~b}$ strain SHL003 (22 contigs, $3.00 \mathrm{Mb}, 476,214$ bp N50 contig size, and 2964 identified genes). These four

Table 2 Distribution of PMSC mutations and codon deletions in inIA of 51 isolates among 120 L. monocytogenes obtained from food and human clinical samples

\begin{tabular}{|c|c|c|c|c|c|c|c|c|c|}
\hline \multirow[t]{2}{*}{ Serogroup } & \multicolumn{8}{|l|}{ InIA PMSC } & \multirow{2}{*}{$\begin{array}{l}\text { Codon } \\
\text { deletion }\end{array}$} \\
\hline & Food isolates & Human isolates & Type 4 & Type 6 & Type 8 & Type 11 & Type 12 & Type 19 & \\
\hline $1 / 2 a, 3 a$ & 7/38 (18.4\%) & 0/6 (0.0\%) & 2 & 5 & 0 & 0 & 0 & 0 & 1 \\
\hline $1 / 2 b, 3 b, 7$ & $0 / 23(0.0 \%)$ & $0 / 6(0.0 \%)$ & 0 & 0 & 0 & 0 & 0 & 0 & 0 \\
\hline $1 / 2 c, 3 c$ & $43 / 46$ (93.5\%) & $1 / 1(100 \%)$ & 18 & 0 & 6 & 6 & 4 & 10 & 0 \\
\hline Total & 50 & 1 & 20 & 5 & 6 & 6 & 4 & 10 & 1 \\
\hline
\end{tabular}




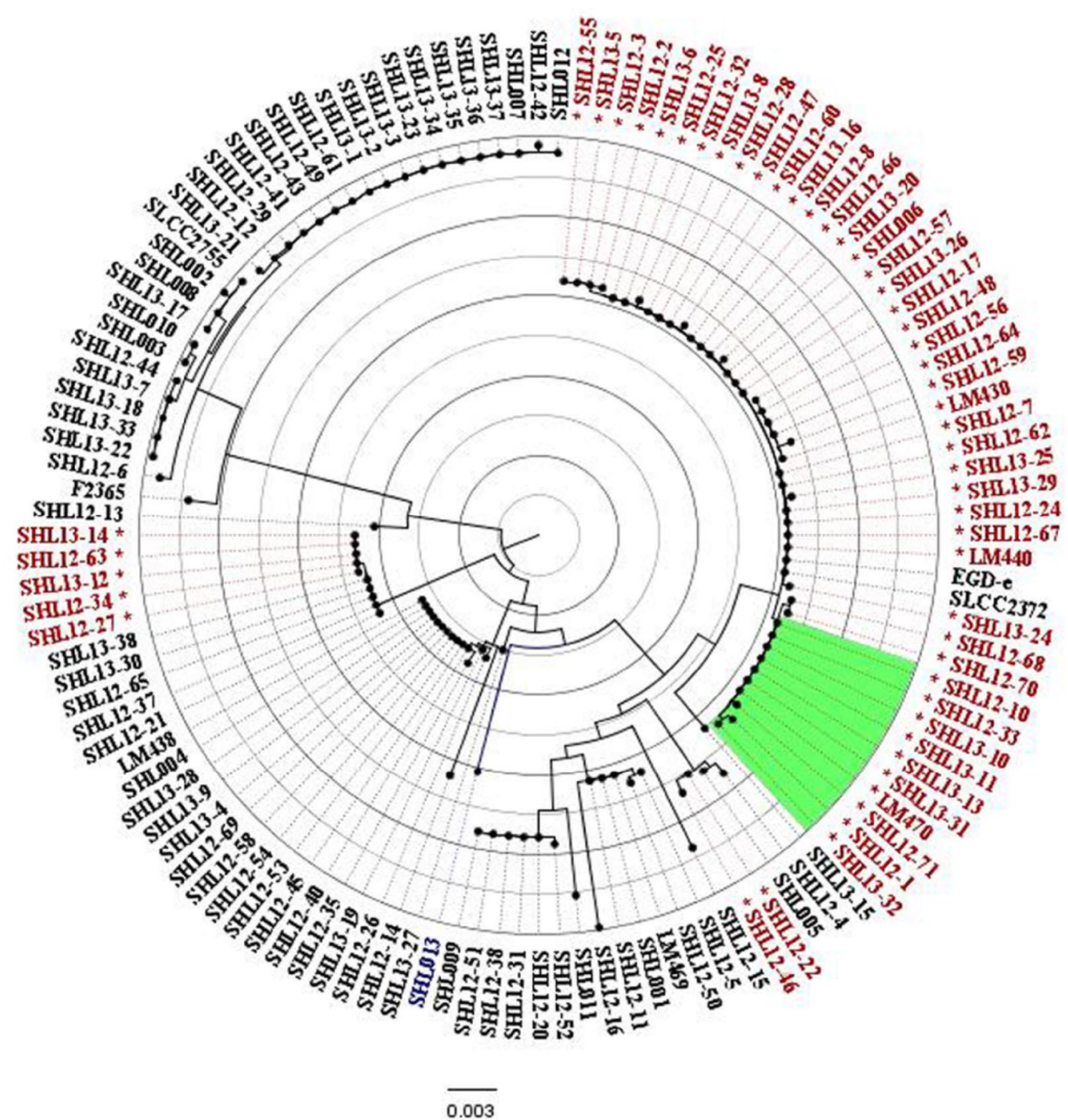

Fig. 1 Phylogenetic tree of 120 L. monocytogenes isolates based on 2400 bp nucleotide sequence of in/A."*" denotes isolates with PMSC mutations in in/A. Ten isolates with mutation type 19 in in/A were grouped together in the region highlighted in green

draft genome sequences have been deposited in GenBank under the accession numbers LRTW00000000, LRTX00000000, LRTY00000000, and LVYC00000000.

Additional 38 genomes were included for the phylogenetic analysis, resulting in 2247 core genes shared by the 42 genomes, and 153,382 SNPs. The 42 L. monocytogenes genomes were divided into two lineages based on the phylogenetic tree (Fig. 2). Serotype1/2c isolates carrying PMSCs in inlA were grouped together with nearly identical core genes sequences with SNPs ranging from 62 to 133. SHL006, LM430, LM440, LM470 and SHL12-2 with different inlA mutation types (types $12,11,4$ and 19 , respectively) were also grouped together with the range of 56-109 SNPs. Human isolate SHL006 with PMSC in inlA was grouped together with two isolates with full length inlA, only 134 SNPs difference between them. SHL12-22 with inlA mutation type 4 and SHL13-12 with inlA mutation type 6 were grouped into different subgroups; SHL12-22 displayed 27,265 SNP differences from SHL13-12. Both of these $1 / 2 \mathrm{a}$ isolates also retained divergent distances from $1 / 2 \mathrm{c}$ isolates that carried PMSCs. Although SHL12-22 and LM 440 carried the same mutation type in inlA (type 4), there was a difference of 21,981 SNPs between the core genes in their genomes. 


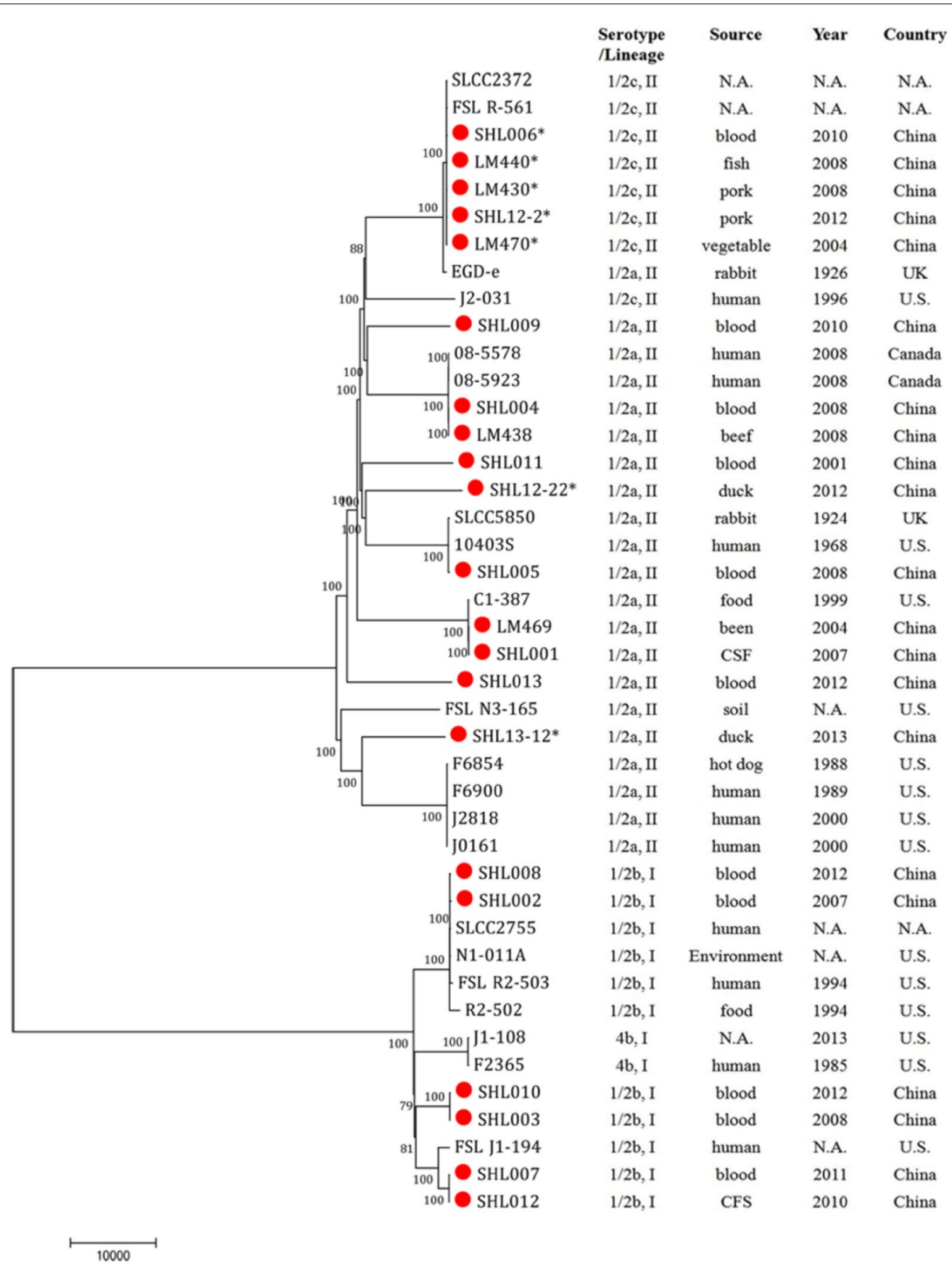

Fig. 2 Phylogenetic tree of 42 L. monocytogenes genomes. A total of 153,382 SNPs in 2247 core genes were identified. The 21 L. monocytogenes genomes from China (our current and previous studies) are identified in red. PMSC mutations are marked with "*"

Invasion of Caco- 2 cells by L. monocytogenes

The $21 \mathrm{~L}$. monocytogenes isolates that were tested for their ability to invade human Caco- 2 cells, included: SHL006 with inlA mutation type 12; LM430 with mutation type 11; LM440 with mutation type 4; LM470 with mutation type 19; SHL12-2 with mutation type 8; SHL1222 with mutation type 4, SHL13-12 with mutation type 6 (Additional file 1: Table S1), and 14 isolates with fulllenghth $i n l A$. Results of the invasion assay are presented in Fig. 3 and reported as $\log 10 \mathrm{CFU} / \mathrm{mL} \pm$ standard 
deviation. A significant difference $(P<0.01)$ in the means of the bacterial count was observed between isolates with full-length and truncated inlA profiles. Serotype 1/2b isolates showed high invasion efficiencies $(4.28 \pm 0.39$ $(\log 10 \mathrm{CFU} / \mathrm{mL})$ ). Two food isolates (LM440 and SHL12-2) with PCMS mutations in inlA, and L. innocua ATCC33090 failed to invade Caco-2 human epithelial cells. Food isolate LM470, that carried PCMS mutation type 19, exhibited lower bacterial counts $(1.84 \pm 0.30$ $(\log 10 \mathrm{CFU} / \mathrm{mL}))$. A correlation between the existence of PMSC mutations in inlA and weak Caco-2 cell invading ability was found among the isolates examined (Pearson's coefficient $0.927, P<0.01$ ). But the internalin profiles were not associated with their ability to invade human Caco-2 cells.

Among the clinical isolates, SHL006 (obtained from a human blood sample) exhibited a lower mean of the bacterial count, $1.95 \pm 0.45(\log 10 \mathrm{CFU} / \mathrm{mL})$. The bacterial count from the isolates with full-length inlA that caused death in Shanghai was greater than those with PMSC mutations. However, SHL013 with a deletion in inlA recovered from cerebrospinal fluid showed high invasion efficiencies $(4.81 \pm 0.34(\log 10 \mathrm{CFU} / \mathrm{mL}))$. SHL001 from cerebrospinal fluid also exhibited a higher bacterial count $(3.85 \pm 0.15(\log 10 \mathrm{CFU} / \mathrm{mL}))$.

\section{Discussion}

Listeria monocytogenes is an important foodborne pathogen with a significant public health concern worldwide. The pathogen is able to invade a number of nonphagocytic cells. The invasion efficiency of $L$. monocytogenes varies with cell lines. Entry into cells has been investigated in great detail since the discovery of invasion proteins internalin (InlA) and InlB, and their respective receptors E-cadherin (E-cad) and Met [9]. For instance, InlC may play a role when bacteria are intracytosolic, in the process of active intercellular spread [25]. Individual inactivation of internalins from the inlGHE gene cluster appears to modulate Listeria InlB dependent invasion of endothelial cells [2]. An inlJ deletion mutant significantly attenuated virulence after intravenous infections of Balb/c mice or oral inoculation of hEcad mice [45]. Drolia et al. show that L. monocytogenes employs Listeria adhesion protein (LAP) to exploit epithelial innate defenses and induce intestinal barrier dysfunction [12, 13]. Meanwhile, the pathogen may benefit from synergetic cooperation of different factors (Ami, p60, ActA, Auto) in invasion $[5,33,42,53,56]$.

Virulence potential is known to vary among different strains of L. monocytogenes [6, 11, 27, 36]. Multiple distinct mutations leading to PMSC in inlA have previously

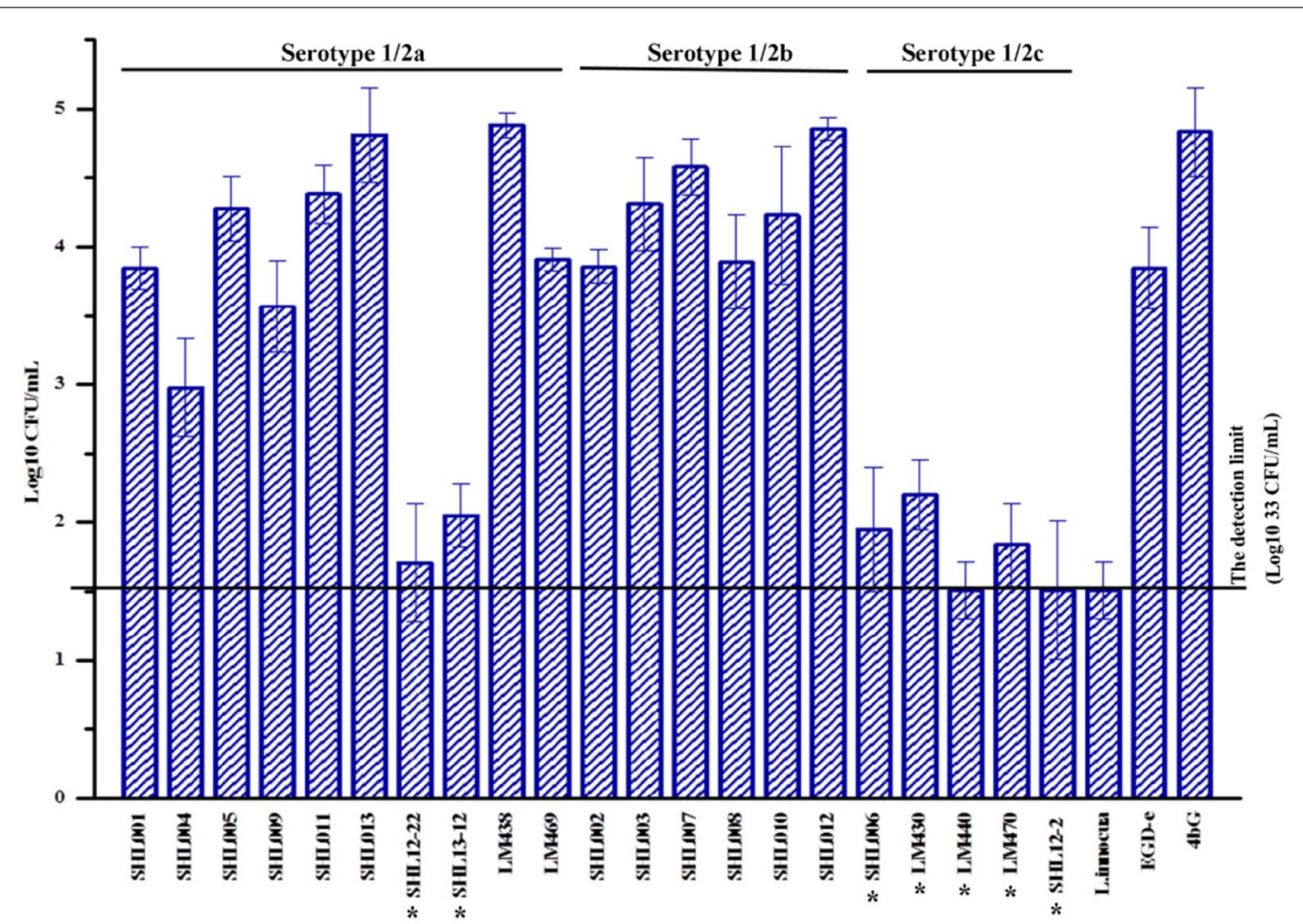

Fig. 3 The ability of 21 L. monocytogenes isolates to invade human Caco-2 epithelial cells in vitro. Isolates with inlA PMSC mutations are marked with "*". A black square indicates in/A positive 
been reported [26, 32, 36]. To date, 21 mutation types of inlA have been found $[19,20,58]$. Isolates carrying a PMSC mutation in inlA produce a truncated form of InlA that is secreted rather than anchored to the bacterial cell wall [37]. Food-derived isolates with PMSC mutations have been reported at similar frequency levels to those reported in the present study (30-45\%) [48], and PMSC mutations in $1 / 2 \mathrm{c}$ isolates were found to be more common. Among the serotype $1 / 2 \mathrm{c}$ isolates obtained from foods, we found that $43(93.48 \%, \mathrm{n}=46)$ carried PMSC mutations in inlA. Kanki et al. also reported that $1 / 2 \mathrm{c}$ isolates from food all carried PMSCs in Japan [26]. Two other studies have provided initial evidence that L. monocytogenes known to carry inlA PMSC mutations rarely cause human listeriosis in the United States [22, 37]. Furthermore, Van Stelten et al. have reported that a significantly $(P<0.001)$ greater proportion of RTE food isolates (45.0\%) carried a PMSC mutation in inlA than human clinical isolates (5.1\%) in the United States [58]. Genetic changes leading to a PMSC mutation in inlA therefore represent a molecular marker for $L$. monocytogenes virulence attenuation [26], which could therefore be used to predict the human health risk associated with consumption of food contaminated by L. monocytogenes.

The majority of virulence genes have been detected in the WGS data, providing a fast and cheaper alternative to conventional typing techniques [30]. In this study, we compared core genes in the 42 genomes of L. monocytogenes from diverse sources and regions, and found that some of these genomes carried different PMSCs in inlA. Serotype $1 / 2 \mathrm{c}$ showed a clonal structure, and had identical characteristics in their genomes even if they had different mutation types of inlA. In contrast, L. monocytogenes serotypes $1 / 2 \mathrm{a}$ with PMSCs in inlA displayed a divergent structure. Mutations of inlA were in fact random. Comparative sequence analysis revealed differences between the human and food isolates. Overall, we found that L. monocytogenes from China contained extensive diversification, consistent with the findings of Zhang et al. [62].

Many investigators have used cell culture assays to determine differences in virulence among strains of $L$. monocytogenes. In this study, the invasion ability of 13 human and 8 food isolates of L. monocytogenes exhibiting PMSC mutations was evaluated via a Caco-2 cell invasion assay. L. monocytogenes isolates with PMSCs showed reduced invasion efficiencies. A significant correlation between the existence of PMSC mutations in inlA and a weakness in the ability of L. monocytogenes isolates to invade Caco-2 cells was observed. This finding is consistent with those of several previous studies in France, Japan and the United State, reporting that L. monocytogenes isolates with PMSC mutations displayed reduced invasion of Caco-2 cells in vitro $[26,36,54]$. Such isolates have also been shown to exhibit low virulence levels in mammalian hosts [36]. It appears that serotype $1 / 2 \mathrm{c}$ isolates found in foods invariably carry a high rate of PMSC mutations, but the frequency in those from human cases is lower [32].

Listeria monocytogenes from China have recently been shown to display a divergent population structure [62]. In the present study, an isolate derived from a vegetable source (LM470) which carried PMSC mutation type 19, showed reduced invasion ability into human Caco-2 epithelial cells. Meanwhile, the other nine isolates carrying the same PCMS mutations were from chicken, pork and beef, respectively. InlA mutation isolates had a widespread distribution and we also noticed $L$. monocytogenes isolates with PMSCs might still cause listeriosis (human isolate SHL006 carrying a PMSC mutation), which have been reported in previous studies [17, 21, 31, 58]. It is also important to note that L. monocytogenes infection is related to additional factors such as dietary intake, and health condition (pregnant women and the elderly) [24].

\section{Conclusions}

Our results in this study have revealed that a proportion of L. monocytogenes isolates from food and humans in Shanghai, China, exhibited a reduced ability to invade human intestinal epithelial cells in vitro, and that this is linked to the presence of PMSC mutations in inlA. The PMSC mutations are commonly carried by serotype $1 / 2 \mathrm{c}$ isolates that had identical characteristics in their genomes and were less prevalent among human L. monocytogenes. In agreement with previously published studies [26, 36, 39, 57], L. monocytogenes carrying PMSC mutations showed reduced invasion ability and attenuated virulence. It is correlated with the distribution of $L$. monocytogenes in food and humans. However, isolates with PMSC in inlA have been associated with human illness, and pose a risk to cause foodborne listeriosis due to their high prevalence in food. A better understanding of relationship between genetics and virulence in L. monocytogenes and their association with L. monocytogenes invasion can provide tools to develop more effective diagnostic strategies in reducing risk of human listeriosis.

\section{Additional file}

Additional file 1: Table S1. Characterization of specific alleles in In|A of 120 Listeria monocytogenes isolates. 


\section{Acknowledgements}

We would like to thank MogoEdit (http://www.mogoedit.com) for providing linguistic assistance during the preparation of this manuscript.

\section{Authors' contributions}

XS and JM designed the experiment and revised the manuscript, XS performed the experiment, analyzed the data, and drafted the manuscript. GC, DZ and JZ analyzed the genome data and revised the manuscript. HP, DK, XY and XX helped performed the experiment, collected the samples. All authors read and approved the final manuscript.

\section{Funding}

This study was funded by Ministry of Science and Technology of China (2016YFE0106100).

\section{Availability of data}

These four draft genomes have been deposited in GenBank under the accession numbers: SHL003, LVYC00000000; SHL12-2, LRTW00000000; SHL12-22, LRTX00000000; SHL13-12L, RTY00000000.

\section{Ethics approval and consent to participate}

The study was approved by Shanghai Jiaotong University Ethics Committee.

\section{Consent for publication}

Not applicable.

\section{Competing interests}

The authors declare that they have no competing interests.

\section{Author details}

${ }^{1}$ Department of Food Science and Technology, MOST-USDA Joint Research Center for Food Safety, School of Agriculture and Biology, State Key Lab of Microbial Metabolism, Shanghai Jiao Tong University, Shanghai 200240, China. ${ }^{2}$ Department of Nutrition \& Food Science, University of Maryland, College Park, MD 20742, USA. ${ }^{3}$ Shanghai Municipal Center for Disease Control and Prevention, Shanghai 200336, China.

Received: 2 January 2019 Accepted: 29 May 2019

Published online: 10 June 2019

\section{References}

1. Akrami-Mohajeri F, Derakhshan Z, Ferrante M, Hamidiyan N, Soleymani M, Conti GO, Tafti RD. The prevalence and antimicrobial resistance of Listeria spp in raw milk and traditional dairy products delivered in Yazd, central Iran (2016). Food Chem Toxicol. 2018;114:141-4.

2. Bergmann B, Raffelsbauer D, Kuhn M, Goetz M, Hom S, Goebel W. InIAbut not InIB-mediated internalization of Listeria monocytogenes by nonphagocytic mammalian cells needs the support of other internalins. Mol Microbiol. 2002;43(3):557-70.

3. Bierne H, Sabet C, Personnic N, Cossart P. Internalins: a complex family of leucine-rich repeat-containing proteins in Listeria monocytogenes. Microbes Infect. 2007;9:1156-66.

4. Boisrobert C, Stjepanovic A, Oh S, Lelieveld H. Ensuring global food safety: exploring global harmonization. 1st ed. Amsterdam: Elsevier; 2010.

5. Cabanes D, Dussurget O, Dehoux P, Cossart P. Auto, a surface associated autolysin of Listeria monocytogenes required for entry into eukaryotic cells and virulence. Mol Microbiol. 2004;51(6):1601-14.

6. Camargo AC, Woodward JJ, Call DR, Nero LA. Listeria monocytogenes in food-processing facilities, food contamination, and human listeriosis: the brazilian scenario. Foodborne Pathog Dis. 2017;14:623-36.

7. Chen J, Luo X, Jiang L, Jin P, Wei W, Liu D, Fan W. Molecular characteristics and virulence potential of Listeria monocytogenes isolates from Chinese food systems. Food Microbiol. 2009;26:103-11.

8. Chen M, Cheng J, Wu Q, Zhang J, Chen Y, Xue L, Lei T, Zeng H, Wu S, Ye Q, Bai J, Wang J. Occurrence, antibiotic resistance, and population diversity of Listeria monocytogenes isolated from fresh aquatic products in China. Front Microbiol. 2018;9:2215.
9. Cossart P. Illuminating the landscape of host-pathogen interactions with the bacterium Listeria monocytogenes. Proc Natl Acad Sci USA 2011;108:19484-91.

10. Cristina DC, Andrew RP, Sally AH, Graham C. Fletcher Listeria monocytogenes associated with New Zealand seafood production and clinical cases: unique sequence types, truncated InIA, and attenuated invasiveness. Appl Environ Microbiol. 2014;80(4):1489-97.

11. Cruz CD, Pitman AR, Harrow SA, Fletcher GC. Listeria monocytogenes associated with New Zealand seafood production and clinical cases: unique sequence types, truncated InIA, and attenuated invasiveness. Appl Environ Microbiol. 2014;80:1489-97.

12. Drolia R, Bhunia AK. Crossing the intestinal barrier via Listeria adhesion protein and internalin A. Trends Microbiol. 2019. https://doi.org/10.1016/j. tim.2018.12.007.

13. Drolia R, Tenguria S, Durkes AC, Turner JR, Bhunia AK. Listeria adhesion protein induces intestinal epithelial barrier dysfunction for bacterial translocation. Cell Host Microbe. 2018;23(4):470-84.

14. Enright AJ, Van Dongen S, Ouzounis CA. An efficient algorithm for largescale detection of protein families. Nucleic Acids Res. 2002;30:1575-84.

15. Felicio MT, Hogg T, Gibbs P, Teixeira P, Wiedmann M. Recurrent and sporadic Listeria monocytogenes contamination in alheiras represents considerable diversity, including virulence-attenuated isolates. Appl Environ Microbiol. 2007;73:3887-95.

16. Ferreira da Silva M, Ferreira V, Magalhães $R$, Almeida G, Alves A, Teixeira $P$. Detection of premature stop codons leading to truncated internalin $A$ among food and clinical strains of Listeria monocytogenes. Food Microbiol. 2017;63:6-11.

17. Fravalo P, Cherifi T, Neira Feliciano KD, Letellier A, Fairbrother JH, Bekal S. Characterisation of InIA truncation in Listeria monocytogenes isolates from farm animals and human cases in the province of Quebec. Vet Rec Open. 2017:4(1):e000199.

18. Gaillard JL, Berche P, Frehel C, Gouin E, Cossart P. Entry of L. monocytogenes into cells is mediated by internalin, a repeat protein reminiscent of surface antigens from gram-positive cocci. Cell. 1991;65(7):1127-41.

19. Gelbíčová T, Koláčková I, Pantůček R, Karpíšková R. A novel mutation leading to a premature stop codon in in/A of Listeria monocytogenes isolated from neonatal listeriosis. New Microbiol. 2015;38:293-6.

20. Gelbíčová T, Pantůček R, Karpíšková R. Virulence factors and resistance to antimicrobials in Listeria monocytogenes serotype 1/2c isolated from food. J Appl Microbiol. 2016;121:569-76.

21. Goulet V, Hedberg C, Le Monnier A, de Valk H. Increasing incidence of listeriosis in France and other European countries. Emerg Infect Dis. 2008;14:734-40.

22. Gray MJ, Zadoks RN, Fortes ED, Dogan B, Cai S, Chen Y, Scott VN, Gombas DE, Boor KJ, Wiedmann M. Listeria monocytogenes isolates from foods and humans form distinct but overlapping populations. Appl Environ Microbiol. 2004;70:5833-41.

23. Heidarzadeh S, Dallal MMS, Pourmand MR, Pirjani R, Foroushani AR, Noori $M$, Naseri AB. Prevalence, antimicrobial susceptibility, serotyping and virulence genes screening of Listeria monocytogenes strains at a tertiary care hospital in Tehran, Iran. Iran J Microbiol. 2018;10(5):307-13.

24. Holch A, Ingmer H, Licht TR, Gram L. Listeria monocytogenes strains encoding premature stop codons in in/A invade mice and guinea pig fetuses in orally dosed dams. J Med Microbiol. 2013;62(Pt 12):1799-806.

25. Joseph B, Przybilla K, Stühler C, Schauer K, Slaghuis J, Fuchs TM, Goebel $W$. Identification of Listeria monocytogenes genes contributing to intracellular replication by expression profiling and mutant screening. J Bacteriol. 2006;188:556-568

26. Kanki M, Naruse H, Taguchi M, Kumeda Y. Characterization of specific alleles in InIA and PrfA of Listeria monocytogenes isolated from foods in Osaka, Japan and their ability to invade Caco-2 cells. Int J Food Microbiol. 2015;211:18-22.

27. Kleta S, Hammerl JA, Dieckmann R, Malorny B, Borowiak M, Halbedel S, Prager R, Trost E, Flieger A, Wilking H, Vygen-Bonnet S, Busch U, Messelhäußer U, Horlacher S, Schönberger K, Lohr D, Aichinger E, Luber P, Hensel A, Al Dahouk S. Molecular tracing to find source of protracted invasive listeriosis outbreak, Southern Germany, 2012-2016. Emerg Infect Dis. 2017;23:1680-3.

28. Kotzamanidis C, Papadopoulos T, Vafeas G, Tsakos P, Giantzi V, Zdragas A. Characterization of Listeria monocytogenes from encephalitis cases of 
small ruminants from different geographical regions, in Greece. J Appl Microbiol. 2019;1:1. https://doi.org/10.1111/jam.14244.

29. Li L, Stoeckert CJ, Roos D. OrthoMCL: identification of ortholog groups for eukaryotic genomes. Genome Res. 2003;13:2178-89.

30. Lindsey RL, Pouseele H, Chen JC, Strockbine NA, Carleton HA. Implementation of whole genome sequencing (WGS) for identification and characterization of shiga toxin-producing Escherichia coli (STEC) in the United States. Front Microbiol. 2016;7:766.

31. Mammina C, Parisi A, Guaita A, Aleo A, Bonura C, Nastasi A, Pontello M. Enhanced surveillance of invasive listeriosis in the Lombardy region, Italy, in the years 2006-2010 reveals major clones and an increase in serotype 1/2a. BMC Infect Dis. 2013;13:152.

32. Manuel CS, Van Stelten A, Wiedmann M, Nightingale KK, Orsi RH. Prevalence and distribution of Listeria monocytogenes in/A alleles prone to phase variation and in/A alleles with premature stop codon mutations among human, food, animal and environmental isolates. Appl Environ Microbiol. 2015;81:8339-45.

33. Milohanic E, Jonquieres R, Cossart P, Berche P, Gaillard JL. The autolysin Ami contributes to the adhesion of Listeria monocytogenes to eukaryotic cells via its cell wall anchor. Mol Microbiol. 2001;39(5):1212-24.

34. Moreno-Hagelsieb G, Latimer K. Choosing BLAST options for better detection of orthologs as reciprocal best hits. Bioinformatics. 2008;24:319-24

35. Niemann HH, Jäger V, Butler PJ, van den Heuvel J, Schmidt S, Ferraris D, Gherardi E, Heinz DW. Structure of the human receptor tyrosine kinase met in complex with the Listeria invasion protein InIB. Cell. 2007:130:235-46.

36. Nightingale KK, Ivy RA, Ho AJ, Fortes ED, Njaa BL, Peters RM, Wiedmann M. in/A premature stop codons are common among Listeria monocytogenes isolates from foods and yield virulence-attenuated strains that confer protection against fully virulent strains. Appl Environ Microbiol. 2008;74:6570-83.

37. Nightingale KK, Windham K, Martin KE, Yeung M, Wiedmann M. Select Listeria monocytogenes subtypes commonly found in foods carry distinct nonsense mutations in in/A, leading to expression of truncated and secreted internalin $A$, and are associated with a reduced invasion phenotype for human intestinal epithelial cells. Appl Environ Microbiol. 2005:71:8764-72.

38. Nikitas G, Deschamps C, Disson O, Niault T, Cossart P, Lecuit M. Transcytosis of Listeria monocytogenes across the intestinal barrier upon specific targeting of goblet cell accessible E-cadherin. J Exp Med. 2011;208:2263-77.

39. Orsi RH, Ripoll DR, Yeung M, Nightingale KK, Wiedmann M. Recombination and positive selection contribute to evolution of Listeria monocytogenes in/A. Microbiol. 2007;153:2666-78.

40. Pentecost M, Otto G, Theriot JA, Amieva MR. Listeria monocytogenes invades the epithelial junctions at sites of cell extrusion. PLoS Pathog. 2006;2:e3.

41. Pereira JG, Soares VM, Tadielo LE, Dos Santos EAR, Lopes GV, da Cruz Payão Pellegrini D, Duval EH, da Silva WP. Foods introduced into Brazil through the border with Argentina and Uruguay: pathogen detection and evaluation of hygienic-sanitary quality. Int J Food Microbiol. 2018.283.22-7.

42. Pilgrim S, Kolb-Maurer A, Gentschev I, Goebel W, Kuhn M. Deletion of the gene encoding p60 in Listeria monocytogenes leads to abnormal cell division and loss of actin-based motility. Infect Immun. 2003;71(6):3473-84.

43. Rasmussen OF, Skouboe P, Dons L, Rossen L, Olsen JE. Listeria monocytogenes exists in at least three evolutionary lines: evidence from flagellin, invasive associated protein and listeriolysin $\mathrm{O}$ genes. Microbiology. 1995;141:2053-61.

44. Ruckerl I, Muhterem-Uyar M, Muri-Klinger S, Wagner KH, Wagner M, StessI B. L. monocytogenes in a cheese processing facility: learning from contamination scenarios over three years of sampling. Int J Food Microbiol. 2014;189:98-105.

45. Sabet C, Lecuit M, Cabanes D, Cossart P, Bierne H. LPXTG protein InIJ, a newly identified internalin involved in Listeria monocytogenes virulence. Infect Immun. 2005;73:6912-22.

46. Schubert WD, Urbanke C, Ziehm T, Beier V, Machner MP, Domann E, Wehland J, Chakraborty T, Heinz DW. Structure of internalin, a major invasion protein of Listeria monocytogenes, in complex with its human receptor E-cadherin. Cell. 2002;111:825-36.
47. Seveau S, Pizarro-Cerda J, Cossart P. Molecular mechanisms exploited by Listeria monocytogenes during host cell invasion. Microbes Infect. 2007:9:1167-75.

48. Shen J, Rump L, Zhang Y, Chen Y, Wang X, Meng J. Molecular subtyping and virulence gene analysis of Listeria monocytogenes isolates from food. Food Microbiol. 2013;35:58-64.

49. Sievers F, Wilm A, Dineen D, Gibson TJ, Karplus K, Li W, Lopez R, McWilliam H, Remmert M, Söding J, Thompson JD, Higgins DG. Fast, scalable generation of high-quality protein multiple sequence alignments using Clustal Omega. Mol Syst Biol. 2011;7:539.

50. Skowron K, Kwiecińska-Piróg J, Grudlewska K, Świeca A, Paluszak Z, Bauza-Kaszewska J, Wałecka-Zacharska E, Gospodarek-Komkowska E. The occurrence, transmission, virulence and antibiotic resistance of Listeria monocytogenes in fish processing plant. Int J Food Microbiol. 2018;3(282):71-83.

51. Su X, Cao G, Kuang D, Zhang J, Chen Y, Allard M, Brown E, Shi X, Meng J, Xu X. Draft genome sequences of three Listeria monocytogenes isolates from foods in China. Genome Announc. 2017:5:e00220-17.

52. Su X, Zhang J, Shi W, Yang X, Li Y, Pan H, Kuang D, Xu X, Shi X, Meng J. Molecular characterization and antimicrobial susceptibility of Listeria monocytogenes isolated from foods and humans. Food Control. 2016;70:96-102.

53. Suarez M, Gonzalez-Zorn B, Vega Y, Chico-Calero I, Vázquez-Boland JA. A role for ActA in epithelial cell invasion by Listeria monocytogenes. Cell Microbiol. 2001;3(12):853-64.

54. Tamburro M, Lucia SM, Grazia AM, Fanelli I, Minelli F, Ripabelli G. Evaluation of transcription levels of inlA, inlB, hly, bsh and prfA genes in Listeria monocytogenes strains using quantitative reverse-transcription PCR and ability of invasion into human CaCo-2 cells. FEMS Microbiol Lett. 2015;362:fnv018.

55. Tamura K, Peterson D, Peterson N, Stecher G, Nei M, Kumar S. MEGA5: molecular evolutionary genetics analysis using maximum likelihood, evolutionary distance, and maximum parsimony methods. Mol Biol Evol. 2011;28:2731-9.

56. Travier L, Guadagnini S, Gouin E, Dufour A, Chenal-Francisque V, Cossart P, Olivo-Marin JC, Ghigo JM, Disson O, Lecuit M. ActA promotes Listeria monocytogenes aggregation, intestinal colonization and carriage. PLoS Pathog. 2014:9(1):e1003131.

57. Van Stelten A, Nightingale KK. Development and implementation of a multiplex single-nucleotide polymorphism genotyping assay for detection of virulence-attenuating mutations in the Listeria monocytogenes virulence-associated gene in/A. Appl Environ Microbiol. 2008;74:7365-75.

58. Van Stelten A, Simpson J, Ward T, Nightingale KK. Revelation by singlenucleotide polymorphism genotyping that mutations leading to a premature stop codon in in/A are common among Listeria monocytogenes isolates from ready-to-eat foods but not human listeriosis cases. Appl Environ Microbiol. 2010;76:2783-90.

59. Van Stelten A, Simpson JM, Chen Y, Scott VN, Whiting RC, Ross WH, Nightingale KK. Significant shift in median guinea pig infectious dose shown by an outbreak-associated Listeria monocytogenes epidemic clone strain and a strain carrying a premature stop codon mutation in in/A. Appl Environ Microbiol. 2011;77:2479-87.

60. Wang H, Luo L, Zhang Z, Deng J, Wang Y, Miao Y, Zhang L, Chen X, Liu X, Sun S, Xiao B, Li Q, Ye C. Prevalence and molecular characteristics of Listeria monocytogenes in cooked products and its comparison with isolates from listeriosis cases. Front Med. 2018;12:104-12.

61. Wang P, Yang H, Hu Y, Yuan F, Zhao G, Zhao Y, Cheng Y. Characterization of Listeria monocytogenes isolates in import food products of China from 8 provinces between 2005 and 2007. J Food Sci. 2012;77:M212-6.

62. Zhang J, Cao G, Xu X, Allard M, Li P, Brown E, Yang X, Pan H, Meng J. Evolution and diversity of Listeria monocytogenes from clinical and food samples in Shanghai, China. Front Microbiol. 2016;7:1138.

63. Zhang Y, Yeh E, Hall G, Cripe J, Bhagwat AA, Meng J. Characterization of Listeria monocytogenes isolated from retail foods. Int J Food Microbiol. 2007;113:47-53.

\section{Publisher's Note}

Springer Nature remains neutral with regard to jurisdictional claims in published maps and institutional affiliations. 